\title{
Tomato Seed Extract Containing Lycoperoside H Improves Skin Elasticity in Japanese Female Subjects: A Randomized, Placebo-Controlled, Double-Blind Trial
}

\author{
Tatsuya Izumi', Kazuo Yamamoto², Naoko Suzuki², Shin-ichiro Yamashita', Shin-ichiro Iio², \\ Hayata Noguchi' ${ }^{2}$, Toshihiro Kakinuma², Asami Baba' ${ }^{2}$, Shogo Takeda ${ }^{3}$, Wakana Yamada ${ }^{3}$, \\ Hiroshi Shimoda ${ }^{3 *}$
}

\begin{abstract}
${ }^{1}$ Hiroo Dermatology Clinic \& Mentors Inc., 1 \& 2F Hiroo Masugi Annex Bldg., Hiroo, Shibuya-ku, Tokyo, Japan ${ }^{2}$ ORTHOMEDICO Inc., 2F Sumitomo Fudosan Korakuen Bldg., Koishikawa Bunkyo-ku, Tokyo, Japan ${ }^{3}$ Oryza Oil \& Fat Chemical Co., Ltd., 1 Numata, Kitagata-cho, Ichinomiya, Aichi, Japan Email: *kaihatsu@mri.biglobe.ne.jp
\end{abstract}

How to cite this paper: Izumi, T., Yamamoto, K., Suzuki, N., Yamashita, S., Iio, S., Noguchi, H., Kakinuma, T., Baba, A., Takeda, S., Yamada, W. and Shimoda, H. (2021) Tomato Seed Extract Containing Lycoperoside $\mathrm{H}$ Improves Skin Elasticity in Japanese Female Subjects: A Randomized, Placebo-Controlled, Double-Blind Trial. Journal of Cosmetics, Dermatological Sciences and Applications, 11, 217-236. https://doi.org/10.4236/jcdsa.2021.113019

Received: June 9, 2021

Accepted: August 24, 2021

Published: August 27, 2021

\section{Copyright $\odot 2021$ by author(s) and} Scientific Research Publishing Inc. This work is licensed under the Creative Commons Attribution International License (CC BY 4.0).

http://creativecommons.org/licenses/by/4.0/ (c) (i) Open Access

\begin{abstract}
Background and Objective: Tomato seeds are edible seeds unconsciously ingested with the fruit. However, there are few reports regarding the constituents and biological activities of tomato seed extract (TSE). Recently, we found that saponins are major constituents of TSE including lycoperoside $\mathrm{H}$. Previous reports have described that several plant-derived saponins improve skin diseases such as wounds and microangiopathy. Therefore, to discover the effect of TSE on the skin condition, we conducted a clinical trial of TSE (Tomato Seed Extract-P) standardized with lycoperoside $\mathrm{H}$ when orally ingested. Methods: The study was performed as a randomized, double-blind, placebo-controlled study. TSE (200 mg daily) containing $1 \mathrm{mg}$ of lycoperoside $\mathrm{H}$ was used as the active sample. We enrolled 44 Japanese women who have concerns about facial elasticity and relatively low facial skin elasticity. All subjects were randomly allocated into either the active group $(\mathrm{n}=22)$ or the placebo group $(n=22)$ using a computerized random-number generator. Capsules containing either the active sample or a placebo were administered for 8 weeks between October 12, 2020, and January 16, 2021. Facial elasticity, specifically the $\mathrm{R} 7$ value, was evaluated as the primary outcome. The remaining facial $\mathrm{R}$ parameters, upper arm $\mathrm{R}$ parameters, and other skin parameters including epidermal moisture, trans epidermal water loss, dermal parameters, and advanced glycation end products (AGEs) parameters were measured at 0 , 4 , and 8 weeks of ingestion. Blood, urine, and body parameters were also evaluated for safety. Results: Forty-three subjects completed the trial, and the
\end{abstract}


per protocol set comprised 21 subjects in the TSE group and 22 subjects in the placebo group. After ingesting TSE for 8 weeks, the R7 value was significantly higher in the TSE group compared to the placebo group. Furthermore, the change in R7 values from the baseline at 4 and 8 weeks were also higher in the TSE group. Among the secondary outcomes, facial elasticity parameters including R2, R5, R1, and R4 at 4 weeks and facial R5, R1, and R4 and upper arm R2 at 8 weeks were higher in the TSE group. In addition, plasma pentosidine significantly decreased in the TSE group after 8 weeks of ingestion. There were no significant differences in moisture, DermaLab ${ }^{\oplus}$ parameters and AGEs parameters except plasma pentosidine. Laboratory tests revealed no abnormalities suggesting adverse effects of TSE. Conclusions: TSE (200 mg/day) standardized with lycoperoside $\mathrm{H}$ improved the facial elasticity parameters. Thus, daily ingestion of TSE was suggested to be beneficial for maintaining the facial skin elasticity. However, the relationship between the reduction of pentosidine and skin elasticity by TSE ingestion should be clarified through further studies. Trial Registration: UMIN-CTR: UMIN000041881. Foundation: Oryza Oil \& Fat Chemical Co., Ltd.

\section{Keywords}

Tomato Seed, Saponin, Lycoperoside, Skin Elasticity, Cutometer, Pentosidine

\section{Introduction}

Ingestion of tomato fruit is recognized to be beneficial to maintain a healthy skin condition [1] because it contains many types of phytochemicals [2]. Lycopene is a principal, well-known carotenoid in tomato [3] which can reduce the risks of reactive oxygen species [4]. Its photoprotective activity can prevent UV-induced erythema after 10 to 12 weeks of ingestion [5] [6]. The amount of lycopene in daily tomato ingestion is sufficient to protect the skin from photodamage [7]. As well as the photoprotective effects of tomato carotenoids, tomatoes also contain several types of polyphenols such as naringenin [8] and naringenin chalcones [9]. There are no clinical trial reports of naringenin when orally ingested, however, topical application of naringenin micro sponges [10], liposomes [11], and nanoparticles [12] were reported to improve the skin condition such as wound scars [13] and atopic dermatitis [10]. These applications of naringenin were based on anti-inflammatory [14] and anti-allergy [15] [16] effects proved by in vivo models. Furthermore, naringenin protects cultured human keratinocytes [17] and mouse skin [18] [19] from UV damage through anti-photoaging effects [20] and exhibits whitening effects in B16 melanoma cells [21].

As well as lycopene and polyphenols, saponins are a third type of phytochemical found in tomato [22]. Several types of saponins, such as lycoperosides [23] [24], esculeosides [25] [26] [27] [28] [29], and tomatine [30], have been identified in tomatoes. Regarding the biological activities of tomato saponins on the skin condition, Zhou et al. [31] demonstrated that the oral administration of esculeo- 
side B isolated from tomato juice attenuated 2,4-dinitrochlorobenzene-induced type IV allergic dermatitis in mice. On the other hand, esculeoside A was found to inhibit hyaluronidase inhibitory activity and suppress itching in a mouse dermatitis model [32]. Generally, tomato seeds are discarded after squeezing juice or oil extraction. Thus, we performed a constituent study of tomato seeds to find effective use of waste resources and found that lycoperosides are major saponins in the seeds. Furthermore, lycoperoside $\mathrm{H}$ was found to suppress atopic dermatitis-like skin inflammation in IL-33 deficient mice [33].

Despite the above chemical and preclinical studies of tomato saponins, there are no reports of a clinical study of saponins especially on the skin condition. However, several plant extracts containing saponins have been found to have improving effects on skin diseases. For example, Centella asiatica extract containing asiaticosides or centella saponins were found to improve wound appearance after topical [34] and oral [35] application. Moreover, the topical application of escin, a horse chestnut seed saponin, ameliorates diabetic microangiopathy [36] and superficial vein thrombosis [37]. These efficacies were caused by improvement of micro blood circulation [38]. From these reports, TSE was suggested to have beneficial effects on the skin condition. Therefore, we conducted a clinical trial of tomato seed extract (TSE) standardized with lycoperoside $\mathrm{H}$ content on the skin condition.

\section{Materials and Methods}

\subsection{TSE and Lycoperoside $H$}

Tomato Seed Extract-P (Lot. N-027) manufactured by Oryza Oil \& Fat Chemical Co. Ltd. was used as the TSE for the study. The content of lycoperoside $\mathrm{H}$ was $0.5 \%$. The content was determined by HPLC equipped with a charged aerosol detector (Corona ${ }^{\mathrm{TM}} \mathrm{Veo}^{\mathrm{TM}} \mathrm{CAD}$ detector, Thirmo Scientific, USA) [39] and a revered phase HPLC column (CAPCELL PAK C18 SG120, $4.6 \mathrm{~mm}$ i.d. $\times 250$ $\mathrm{mm}$, Osaka Soda Co., Japan). Sixty percent $\mathrm{MeOH}$ containing $0.1 \%$ trifluoro acetic acid was used as a solvent. The injection volume was $10 \mu \mathrm{L}$ and the flow rate was $1 \mathrm{~mL} / \mathrm{min}$. The evaporation temperature and filter setting of the charged aerosol detector were $35^{\circ} \mathrm{C}$ and 5.0 seconds, respectively. The $\mathrm{N}_{2}$ gas pressure was $62.9 \mathrm{psi}$ and the charger voltage was $1.8 \mathrm{kV}$. The range scale was set to 200 pA. Lycoperoside H standard was prepared at Oryza Oil \& Fat Chemical Co. Ltd. Standard lycoperoside $\mathrm{H}$ was dissolved in $\mathrm{MeOH}$ and TSE was dissolved in $60 \%$ $\mathrm{MeOH}$. The approximate analyzing time was $40 \mathrm{~min}$.

\subsection{Participants and Grouping}

All subjects were recruited between September 17 and October 24, 2020, through the Go106 website (https://www.go106.jp/) operated by ORTHOMEDICO Inc. The inclusion criteria were healthy Japanese female adults (20 years old or more) with concerns about facial skin elasticity. The exclusion criteria were as follows:

1) Current or previous cancer, heart failure, or myocardial infarction. 
2) Subjects with a heart pacer or an implantable cardioverter defibrillator.

3) Current treatment for arrhythmia, hepatitis, nephritis, rheumatoid arthritis, cerebrovascular disease, diabetes, hyperlipidemia, hypertension, or other chronic diseases.

4) Current use of medications or dietary supplements or beverages.

5) Subjects with allergic reactions to medicines or foods related to tomatoes.

6) Pregnancy, lactation, or expected/planned pregnancy during the study period.

7) Subjects currently participating in another clinical trial or who had participated in one within the previous 3 months.

8) Subjects who have had plastic surgeries.

9) Subjects who have daily skin care therapy such as esthetic treatments or using facial beauty appliances.

10) Subjects who use skin care products daily except creams, serums, all-in-one cosmetics, facial packs, face lotions, face emulsions, and sunscreens.

11) Subjects who have been diagnosed as having atopic dermatitis before.

12) Subjects determined to be inappropriate for the study for other reasons by the attending physician.

13) Subjects who have the risk of disrupting their normal daily routine such as shift work or long trips.

14) Subjects who cannot avoid sunburn or exposure to sunlight for a long time.

The selection criteria were persons who have relatively low facial skin elasticity and were determined to be appropriate for the study by the physician. We chose subjects who had cheeks with relatively lower ratio (R7) of elasticity among candidates at the screening periods. And we regarded them as those who have relatively low facial skin elasticity.

Forty-four female subjects with concerns about facial skin elasticity were selected after they were confirmed to be suitable for the study by a physician (Figure 1). The participants were asked to take test capsules according to the designated method and avoid excessive eating and drinking. In addition, the subjects were requested to refrain from taking dietary supplements and supplemental beverages and maintain a regular lifestyle during the study period. In terms of skin care, excessive sunburn, usage of ceramide cream, and having esthetic treatments were prohibited and the subjects were asked not to change their usual make up style.

One day before testing, the subjects were required to avoid excessive drinking of alcoholic beverages and intensive exercise, and they fasted for 6 hours prior to blood collection except for drinking water. On the screening day, using any type of cosmetics and taking a bath or shower were prohibited.

\subsection{Test Samples and Allocation}

The test samples (indistinguishable brown capsules containing either TSE or a placebo were provided by Oryza Oil \& Fat Chemical Co., Ltd. as hard capsules. 


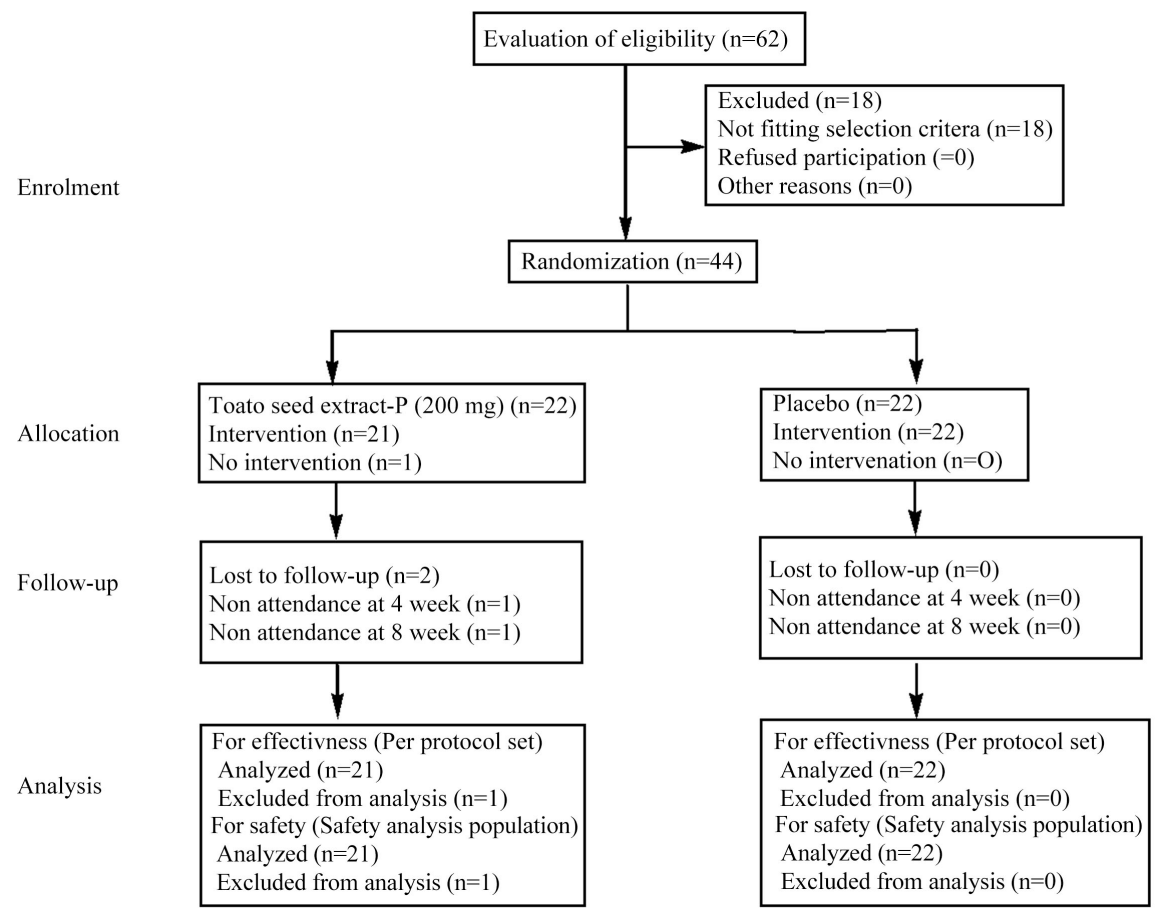

Figure 1. Flowchart showing the characteristics of the subjects.

The active capsules contained $100 \mathrm{mg}$ of Tomato Seed Extract-P (containing 0.5 $\mathrm{mg}$ of lycoperoside $\mathrm{H}$ ) and $50 \mathrm{mg}$ of maltodextrin. Tomato Seed Extract-P consisted of 5\% absolute tomato seed extract and 95\% maltodextrin. The placebo capsules contained $150 \mathrm{mg}$ of maltodextrin.

Oryza Oil \& Fat Chemical Co. Ltd. provided the test samples with red or blue markings on the packages. They strictly kept the sample information until the study period was over.

When the number of registered subjects reached 44, an allocation controller at ORTHOMEDICO Inc. ordered the test capsules according to the provided identification markers and made an allocation sheet and an emergency key. To prepare random numbers for the allocation sheet, Statlight \#11 (Ver. 2.10, Yukms Inc., Japan) was used. The allocation sheet was only provided to the test sample distributers and then strictly concealed with the emergency key by the allocation controller. Then, the test capsules were allocated by class randomization to equalize the allocation ratio (1:1). Allocation was required in order for the means and standard deviations (SD) of cheek elasticity and age not to differ between the groups. Information about allocation was not disclosed to anyone until the subjects for analysis were determined at a clinical conference after study completion.

\subsection{Study Protocol and Skin Parameters}

This randomized, placebo-controlled, double-blind, parallel-group study was carried out at Hiroo Dermatology Clinic \& Mentors Inc. (Tokyo, Japan), and statistical analysis was performed by ORTHOMEDICO Inc. The protocol was 
registered at the University Hospital Medical Information Network Clinical Trials Registry (UMIN000041881). The study was performed between October 12, 2020, and January 16, 2021. The subjects took 2 appropriate capsules (either TSE or a placebo) daily after breakfast for 8 weeks. All the subjects recorded a daily report, including capsule ingestion and menstruation, and answered a questionnaire at 4 and 8 weeks from a physician. Also, the subjects were asked to record a calorie and nutrition diary from 3 days before to the day of screening.

The following parameters were examined at baseline and at 4 and 8 weeks after intake. The R7 value of the cheek at 8 weeks was measured using a cutometer dual MPA580 (Courage + Khazaka Electronic GmbH, Köln, Germany), and was set as the primary outcome. The other elasticity parameters (R1 to R6, R8 and R9) of the cheek at the other periods and R1 to R9 of other parts were set as the secondary outcomes. Each R value was calculated from the deformation length $(\mathrm{mm})$ of Uv (delayed distention), Ue (immediate distention), Uf (total elongation), Ur (immediate retraction), and $U a$ (total recovery) on the chart recorded by a cutometer [40]. R1 is calculated by the difference between Uf and Ua. R2, $\mathrm{R} 5, \mathrm{R} 6$, and R7 are the ratios of Ua/Uf, Ur/Ue, Uv/Ue, and Ur/Uf, respectively. R3 and R4 are the last maximal amplitude and last minimal amplitude, respectively. The cross point of the line drawn vertically from the outer corner of the left eye and the drawn horizontally from the center of the nose was chosen for the evaluation site. The measurement site for the upper arm was defined as the inside of mid-point of the line drawn between the tip of the right shoulder and the elbow. We measured the parameters on the same site. Measurement was performed 3 times and then the average was calculated.

As the other secondary outcomes, the following items were evaluated. The transepidermal water loss (TEWL) was measured using a Tewameter ${ }^{\circledR}$ TM300 (Courage + Khazaka Electronic $\mathrm{GmbH}$ ). The epidermal moisture was measured using a Corneometer CM825 (Courage + Khazaka Electronic GmbH). Skin moisture content and TEWL of each individual site were measured 3 times and once, respectively. DermaLab ${ }^{\circledR}$ (Cortex Technology, Denmark) [41] was used to measure cheek dermal parameters such as intensity, skin thickness, and low echologenic band (LEB). An advanced glycation end products (AGEs) sensor (Air Water Biodesighn Inc, Kobe, Japan) was used for evaluation of finger AGEs. Plasma pentosidine and (carboxylmethyl)lysine (CML) were determined using a VersaMax Microplate Reader (Molecular Devices, LLC., USA) and CircuLex CML/Ne-(Carboxymethyl)lysine ELISA kit (Medical \& Biological Laboratories Co. Ltd., Japan).

\subsection{Laboratory Tests}

The bodyweight, body mass index (BMI), body fat ratio, blood pressure, and pulse rate were measured at all test periods.

Blood and urine were analyzed by LSI Medience Corporation (Tokyo, Japan). All items were examined at baseline and at 4 and 8 weeks after intake. A venous 
blood sample was collected from an arm vein and the following tests were performed for safety assessment.

The hematology components were as follows: counts of red blood cells, leukocytes, platelets, lymphocytes, monocytes, eosinophils and basophils, hemoglobin, and hematocrit. The biochemical components were as follows: total protein, total bilirubin, urea nitrogen, creatinine, uric acid, total cholesterol, low-density lipoprotein (LDL) cholesterol, high-density lipoprotein (HDL) cholesterol, triglyceride, hemoglobin ( $\mathrm{Hb}) \mathrm{Alc}$, blood glucose, glycoalbumin, amylase, creatine kinase (CK), aspartate aminotransferase (AST), alanine transaminase (ALT), $\gamma$-glutamyltransferase ( $\gamma$-GTP), alkaline phosphatase (ALP), lactate dehydrogenase (LDH), leucine aminopeptidase (LAP), chorine esterase, cholecystokinin, $\mathrm{Na}, \mathrm{K}, \mathrm{Cl}, \mathrm{Ca}, \mathrm{Fe}$, inorganic phosphorus, and IgE.

In addition, urine samples were collected for qualitative evaluation, including protein, glucose, urobilinogen, bilirubin, ketone bodies, $\mathrm{pH}$, and occult blood.

\subsection{Ethics, Adherence, and Compliance}

This study was performed according to the Declaration of Helsinki (2013 revision) and was carried out in conformity with ethical considerations. This protocol was approved by the ethics committee of Takara Clinic (Medical Corporation Seishinkai, Tokyo, Japan) on September 15, 2020 (Approved ID: 200900023-0048-21-TC), and substantial deviation from the protocol required authorization by the committee. All subjects received a full explanation about the protocol and purpose of the study before consenting to participation. No subject was part of the sponsoring or funding companies. This study was conducted in accordance with the consort statement.

\subsection{Statistical Analysis}

PPS was chosen as the analysis data set for the primary and secondary outcomes. The results are reported as means and SD. For statistical analysis, one-way analysis of variance (ANOVA) was performed, followed by Dunnett's test. Two-way repeated measures analysis of covariance (ANCOVA) or ANOVA followed by post hoc analysis was performed to detect significant differences between the two groups. The results of the physical examination and blood tests are reported as means and SD. The Student's $t$-test was used to evaluate the significance of differences between before and after ingestion of the test sample. The $\chi^{2}$-test was used for urinalysis parameters, with normal and abnormal values being coded as " 1 " and "0", respectively. We set the significance level at $5 \%$ with no adjustment for multiple comparisons. SPSS (Ver. 23.0, Japan IBM) or Microsoft Excel 2013 was used for statistical evaluation.

\section{Results}

\subsection{Study Performance}

During the study period, one subject in the TSE group refrained to have inter- 
vention after allocation for personal reasons (Figure 1) and was excluded from the analysis in the TSE group from this period. Accordingly, 21 subjects $(52.0 \pm$ 9.2 years) were available for analysis in the TSE group, whereas 22 subjects $(51.2$ \pm 10.0 years) were available for the placebo group. The physical profile of the subjects included in analysis is shown in Table 1 . After 8 weeks of ingestion of TSE, the systolic and diastolic blood pressure significantly decreased compared to the placebo group.

\subsection{Elasticity Parameters}

Table 2 shows the elasticity parameters of the cheek skin. As the primary outcome of the study, the R7 value, meaning skin firmness at 8 weeks in the TSE group, was significantly higher than that of the placebo group. Furthermore, regarding the changes in R7 from the baseline, the values for the TSE group were higher than the placebo group at 4 and 8 weeks. As the secondary outcomes, R2 (gross elasticity) at 4 weeks and R5 (net elasticity) at 4 and 8 weeks in the TSE group were significantly higher than the placebo group. In contrast, R1 (return to original skin) and R4 (last minimal amplitude) at 4 and 8 weeks in the TSE group were lower than the placebo group. Table 3 shows the elasticity parameters of the upper skin. In contrast to the cheek skin, only a few parameters have changed. The R2 value at 8 weeks was higher than the placebo group.

Table 1. Profile of the participants.

\begin{tabular}{|c|c|c|c|c|}
\hline & \multicolumn{2}{|c|}{ Baseline } & \multicolumn{2}{|c|}{$8 \mathrm{~W}$} \\
\hline & TSE & Placebo & TSE & Placebo \\
\hline Age & $52.0 \pm 9.2$ & $51.2 \pm 10.0$ & - & - \\
\hline Height $(\mathrm{cm})$ & $157.0 \pm 5.9$ & $158.4 \pm 6.1$ & - & - \\
\hline Body weight (kg) & $52.6 \pm 10.0$ & $54.2 \pm 10.8$ & $53.1 \pm 10.2$ & $54.5 \pm 10.8$ \\
\hline BMI $\left(\mathrm{kg} / \mathrm{m}^{2}\right)$ & $21.4 \pm 4.4$ & $21.5 \pm 3.6$ & $21.6 \pm 4.5$ & $21.7 \pm 3.6$ \\
\hline Body fat ratio (\%) & $27.4 \pm 9.6$ & $30.1 \pm 7.3$ & $27.5 \pm 9.2$ & $30.3 \pm 7.3$ \\
\hline $\begin{array}{c}\text { Systolic blood } \\
\text { pressure }(\mathrm{mmHg})\end{array}$ & $113.7 \pm 14.6$ & $117.6 \pm 8.3$ & $108.4 \pm 14.1^{* *}$ & $122.1 \pm 12.6$ \\
\hline $\begin{array}{l}\text { Diastolic blood } \\
\text { pressure }(\mathrm{mmHg})\end{array}$ & $73.3 \pm 11.3$ & $75.2 \pm 7.2$ & $69.1 \pm 11.2^{\star}$ & $76.9 \pm 8.3$ \\
\hline Pals rate (bpm) & $76.2 \pm 10.9$ & $71.0 \pm 10.1$ & $72.2 \pm 8.7$ & $69.8 \pm 10.7$ \\
\hline Body temperature $\left({ }^{\circ} \mathrm{C}\right)$ & $32.9 \pm 0.7$ & $32.9 \pm 1.1$ & $32.8 \pm 1.1$ & $32.9 \pm 1.0$ \\
\hline $\operatorname{IgE}(\mathrm{IU} / \mathrm{mL})$ & $361.1 \pm 897.0$ & $375.2 \pm 780.1$ & - & - \\
\hline
\end{tabular}

Data are shown as the mean \pm SD $(\mathrm{n}=21$ for TSE, $\mathrm{n}=22$ for placebo). Student's $t$-test was used for evaluation of significant differences except age $\left(\chi\right.$-squared test). Asterisks indicate significant differences from the placebo at ${ }^{*}: p<0.05$ and ${ }^{* *}: p<0.01$. 
Table 2. Changes in facial skin elasticity parameters measured using a cutometer.

\begin{tabular}{|c|c|c|c|c|c|c|}
\hline & \multicolumn{2}{|c|}{ Baseline } & \multicolumn{2}{|c|}{$4 \mathrm{~W}$} & \multicolumn{2}{|c|}{$8 \mathrm{~W}$} \\
\hline & TSE & Placebo & TSE & Placebo & TSE & Placebo \\
\hline R7 (Skin firmness) & $0.359 \pm 0.044$ & $0.365 \pm 0.048$ & $\begin{array}{c}0.416 \pm 0.091 \\
\left(0.056 \pm 0.090^{\star}\right)\end{array}$ & $\begin{array}{c}0.370 \pm 0.100 \\
(0.004 \pm 0.108)\end{array}$ & $\begin{array}{c}0.356 \pm 0.068^{*} \\
\left(-0.003 \pm 0.057^{*}\right)\end{array}$ & $\begin{array}{c}0.308 \pm 0.069 \\
(-0.058 \pm 0.075)\end{array}$ \\
\hline R1 (Return to original skin, mm) & $0.052 \pm 0.013$ & $0.049 \pm 0.014$ & $\begin{array}{c}0.030 \pm 0.014^{\star} \\
\left(-0.022 \pm 0.020^{\star}\right)\end{array}$ & $\begin{array}{c}0.042 \pm 0.017 \\
(-0.007 \pm 0.022)\end{array}$ & $\begin{array}{c}0.044 \pm 0.021^{\star} \\
\left(-0.008 \pm 0.014^{\star}\right)\end{array}$ & $\begin{array}{c}0.056 \pm 0.014 \\
(0.007 \pm 0.021)\end{array}$ \\
\hline R2 (Gross elasticity, ratio) & $0.641 \pm 0.065$ & $0.064 \pm 0.093$ & $\begin{array}{c}0.739 \pm 0.121^{*} \\
(0.098 \pm 0.126)\end{array}$ & $\begin{array}{c}0.665 \pm 0.142 \\
(0.020 \pm 0.198)\end{array}$ & $\begin{array}{c}0.712 \pm 0.180 \\
(0.069 \pm 0.099)\end{array}$ & $\begin{array}{c}0.642 \pm 0.096 \\
(-0.003 \pm 0.138)\end{array}$ \\
\hline R3 (Last maximal amplitude, $\mathrm{mm}$ ) & $0.143 \pm 0.029$ & $0.144 \pm 0.035$ & $\begin{array}{c}0.115 \pm 0.026 \\
(-0.028 \pm 0.038)\end{array}$ & $\begin{array}{c}0.125 \pm 0.026 \\
(-0.019 \pm 0.037)\end{array}$ & $\begin{array}{c}0.148 \pm 0.053 \\
(0.004 \pm 0.047)\end{array}$ & $\begin{array}{c}0.160 \pm 0.027 \\
(0.016 \pm 0.049)\end{array}$ \\
\hline R4 (Last minimal amplitude, $\mathrm{mm}$ ) & $0.052 \pm 0.013$ & $0.049 \pm 0.014$ & $\begin{array}{c}0.030 \pm 0.014^{*} \\
\left(-0.022 \pm 0.020^{*}\right)\end{array}$ & $\begin{array}{c}0.042 \pm 0.017 \\
(-0.007 \pm 0.022)\end{array}$ & $\begin{array}{c}0.044 \pm 0.021^{\star} \\
\left(-0.008 \pm 0.014^{\star}\right)\end{array}$ & $\begin{array}{c}0.056 \pm 0.014 \\
(0.007 \pm 0.021)\end{array}$ \\
\hline R5 (Net elasticity, ratio) & $0.533 \pm 0.071$ & $0.539 \pm 0.080$ & $\begin{array}{l}0.572 \pm 0.110^{*} \\
(0.039 \pm 0.127)\end{array}$ & $\begin{array}{c}0.507 \pm 0.124 \\
(-0.032 \pm 0.129)\end{array}$ & $\begin{array}{c}0.481 \pm 0.145^{\star} \\
\left(-0.049 \pm 0.083^{\star}\right)\end{array}$ & $\begin{array}{c}0.413 \pm 0.089 \\
(-0.125 \pm 0.103)\end{array}$ \\
\hline R6 (Viscoelasticity, ratio) & $0.483 \pm 0.095$ & $0.473 \pm 0.143$ & $\begin{array}{c}0.381 \pm 0.095 \\
(-0.103 \pm 0.139)\end{array}$ & $\begin{array}{c}0.384 \pm 0.096 \\
(-0.089 \pm 0.169)\end{array}$ & $\begin{array}{c}0.348 \pm 0.111 \\
(-0.126 \pm 0.112)\end{array}$ & $\begin{array}{c}0.349 \pm 0.074 \\
(-0.124 \pm 0.149)\end{array}$ \\
\hline R8 (Total recovery, mm) & $0.092 \pm 0.021$ & $0.095 \pm 0.030$ & $\begin{array}{c}0.086 \pm 0.024 \\
(-0.006 \pm 0.028)\end{array}$ & $\begin{array}{c}0.083 \pm 0.029 \\
(-0.012 \pm 0.039)\end{array}$ & $\begin{array}{c}0.105 \pm 0.040 \\
(0.012 \pm 0.042)\end{array}$ & $\begin{array}{c}0.104 \pm 0.029 \\
(0.009 \pm 0.045)\end{array}$ \\
\hline R9 (Skin fatigue, mm) & $0.000 \pm 0.000$ & $0.000 \pm 0.000$ & $0.000 \pm 0.000$ & $0.000 \pm 0.000$ & $0.000 \pm 0.000$ & $0.000 \pm 0.000$ \\
\hline
\end{tabular}

Actual scores and changes from baseline (in parentheses) are shown as the mean and SD ( $\mathrm{n}=21$ for TSE and $\mathrm{n}=22$ for Placebo). Baseline data were analyzed using Student's $t$-test. After the intervention data, the actual scores were analyzed using the linear mixed model, with the baseline data utilized as covariates and with time, group, group-time interaction, and subject as factors, and changes from baseline were analyzed using the linear mixed model, with time, group, group-time interaction, and subject as factors. An asterisk indicates a significant difference from the placebo at *: $p<0.05$.

Table 3. Changes in upper arm skin elasticity parameters measured using a cutometer.

\begin{tabular}{|c|c|c|c|c|c|c|}
\hline & \multicolumn{2}{|c|}{ Baseline } & \multicolumn{2}{|c|}{$4 \mathrm{~W}$} & \multicolumn{2}{|c|}{$8 \mathrm{~W}$} \\
\hline & TSE & Placebo & TSE & Placebo & TSE & Placebo \\
\hline R7 (Skin firmness) & $0.656 \pm 0.093$ & $0.663 \pm 0.098$ & $\begin{array}{c}0.641 \pm 0.082 \\
(-0.016 \pm 0.107)\end{array}$ & $\begin{array}{c}0.626 \pm 0.094 \\
(-0.037 \pm 0.073)\end{array}$ & $\begin{array}{c}0.622 \pm 0.154 \\
(-0.034 \pm 0.095)\end{array}$ & $\begin{array}{c}0.596 \pm 0.078 \\
(-0.068 \pm 0.079)\end{array}$ \\
\hline R1 (Return to original skin, $\mathrm{mm}$ ) & $0.028 \pm 0.010$ & $0.027 \pm 0.009$ & $\begin{array}{c}0.020 \pm 0.008 \\
(-0.008 \pm 0.012)\end{array}$ & $\begin{array}{c}0.021 \pm 0.006 \\
(-0.006 \pm 0.011)\end{array}$ & $\begin{array}{c}0.027 \pm 0.010 \\
(-0.002 \pm 0.013)\end{array}$ & $\begin{array}{c}0.029 \pm 0.006 \\
(0.002 \pm 0.009)\end{array}$ \\
\hline R2 (Gross elasticity, ratio) & $0.824 \pm 0.079$ & $0.835 \pm 0.056$ & $\begin{array}{c}0.837 \pm 0.047 \\
(0.013 \pm 0.094)\end{array}$ & $\begin{array}{c}0.825 \pm 0.048 \\
(-0.009 \pm 0.062)\end{array}$ & $\begin{array}{c}0.826 \pm 0.185^{*} \\
(0.001 \pm 0.070)\end{array}$ & $\begin{array}{c}0.798 \pm 0.047 \\
(-0.036 \pm 0.056)\end{array}$ \\
\hline R3 (Last maximal amplitude, $\mathrm{mm}$ ) & $0.178 \pm 0.044$ & $0.170 \pm 0.034$ & $\begin{array}{c}0.123 \pm 0.033 \\
(-0.054 \pm 0.054)\end{array}$ & $\begin{array}{c}0.119 \pm 0.023 \\
(-0.050 \pm 0.029)\end{array}$ & $\begin{array}{c}0.151 \pm 0.046 \\
(-0.028 \pm 0.052)\end{array}$ & $\begin{array}{c}0.147 \pm 0.031 \\
(-0.023 \pm 0.046)\end{array}$ \\
\hline R4 (Last minimal amplitude, $\mathrm{mm}$ ) & $0.028 \pm 0.010$ & $0.027 \pm 0.009$ & $\begin{array}{c}0.020 \pm 0.008 \\
(-0.008 \pm 0.012)\end{array}$ & $\begin{array}{c}0.021 \pm 0.006 \\
(-0.006 \pm 0.011)\end{array}$ & $\begin{array}{c}0.027 \pm 0.010 \\
(-0.002 \pm 0.013)\end{array}$ & $\begin{array}{c}0.029 \pm 0.006 \\
(0.002 \pm 0.009)\end{array}$ \\
\hline R5 (Net elasticity, ratio) & $0.869 \pm 0.106$ & $0.877 \pm 0.104$ & $\begin{array}{c}0.834 \pm 0.099 \\
(-0.035 \pm 0.116)\end{array}$ & $\begin{array}{c}0.818 \pm 0.102 \\
(-0.059 \pm 0.088)\end{array}$ & $\begin{array}{c}0.787 \pm 0.191 \\
(-0.079 \pm 0.109)\end{array}$ & $\begin{array}{c}0.749 \pm 0.076 \\
(-0.128 \pm 0.070)\end{array}$ \\
\hline R6 (Viscoelasticity, ratio) & $0.323 \pm 0.070$ & $0.331 \pm 0.088$ & $\begin{array}{c}0.308 \pm 0.078 \\
(-0.016 \pm 0.105)\end{array}$ & $\begin{array}{c}0.314 \pm 0.073 \\
(-0.017 \pm 0.086)\end{array}$ & $\begin{array}{c}0.269 \pm 0.091 \\
(-0.049 \pm 0.057)\end{array}$ & $\begin{array}{c}0.265 \pm 0.072 \\
(-0.067 \pm 0.104)\end{array}$ \\
\hline R8 (Total recovery, mm) & $0.149 \pm 0.040$ & $0.143 \pm 0.034$ & $\begin{array}{c}0.103 \pm 0.029 \\
(-0.046 \pm 0.048)\end{array}$ & $\begin{array}{c}0.098 \pm 0.020 \\
(-0.044 \pm 0.026)\end{array}$ & $\begin{array}{c}0.125 \pm 0.039 \\
(-0.026 \pm 0.044)\end{array}$ & $\begin{array}{c}0.118 \pm 0.028 \\
(-0.025 \pm 0.042)\end{array}$ \\
\hline R9 (Skin fatigue, mm) & $0.000 \pm 0.000$ & $0.000 \pm 0.000$ & $0.000 \pm 0.000$ & $0.000 \pm 0.000$ & $0.000 \pm 0.000$ & $0.000 \pm 0.000$ \\
\hline
\end{tabular}

Actual scores and changes from baseline (in parentheses) are shown as the mean and SD ( $\mathrm{n}=21$ for TSE and $\mathrm{n}=22$ for Placebo). Baseline data were analyzed using Student's $t$-test. After the intervention data, the actual scores were analyzed using the linear mixed model, with the baseline data utilized as covariates and with time, group, group-time interaction, and subject as factors, and changes from baseline were analyzed using the linear mixed model, with time, group, group-time interaction, and subject as factors. An asterisk indicates a significant difference from the placebo at *: $p<0.05$. 


\subsection{Moisture and DermaLab ${ }^{\circledR}$ Parameters}

Table 4 shows the moisture parameters of the cheek and upper arm. However, there were no significant differences in either group for skin moisture or TEWL. Furthermore, the DermaLab ${ }^{\circledast}$ parameters did not change such as LEB, skin thickness, and intensity.

\subsection{AGEs Parameters}

As shown in Table 5, there were no significant differences in the AGEs scores and serum CML. However, serum pentosidine significantly decreased in the TSE group at 8 weeks.

Table 4. Changes in skin moisture and TEWL of the cheek and upper arm and DermaLabo ${ }^{\circledR}$ parameters of the cheek.

\begin{tabular}{|c|c|c|c|c|c|c|}
\hline & \multicolumn{2}{|c|}{ Baseline } & \multicolumn{2}{|c|}{$4 \mathrm{~W}$} & \multicolumn{2}{|c|}{$8 \mathrm{~W}$} \\
\hline & TSE & Placebo & TSE & Placebo & TSE & Placebo \\
\hline \multicolumn{7}{|l|}{ Cheek } \\
\hline Skin moisture & $49.6 \pm 10.0$ & $54.3 \pm 15.2$ & $\begin{array}{c}44.1 \pm 15.6 \\
(-5.6 \pm 15.4)\end{array}$ & $\begin{array}{c}45.5 \pm 11.4 \\
(-8.8 \pm 14.6)\end{array}$ & $\begin{array}{c}46.9 \pm 14.7 \\
(-2.8 \pm 16.9)\end{array}$ & $\begin{array}{c}44.8 \pm 12.7 \\
(-9.5 \pm 15.5)\end{array}$ \\
\hline TEWL $\left(\mathrm{g} / \mathrm{m}^{2} \cdot \mathrm{hr}\right)$ & $17.9 \pm 6.5$ & $14.0 \pm 4.7$ & $\begin{array}{l}18.0 \pm 4.9 \\
(0.1 \pm 4.7)\end{array}$ & $\begin{array}{l}16.4 \pm 3.6 \\
(2.4 \pm 4.0)\end{array}$ & $\begin{array}{c}15.8 \pm 5.9 \\
(-2.2 \pm 3.0)\end{array}$ & $\begin{array}{l}15.1 \pm 5.3 \\
(1.1 \pm 4.8)\end{array}$ \\
\hline \multicolumn{7}{|l|}{ Upper arm } \\
\hline Skin moisture & $34.7 \pm 9.6$ & $35.1 \pm 10.4$ & $\begin{array}{c}31.4 \pm 12.6 \\
(-3.3 \pm 11.7)\end{array}$ & $\begin{array}{c}26.0 \pm 7.0 \\
(-9.2 \pm 12.6)\end{array}$ & $\begin{array}{c}32.3 \pm 8.2 \\
(-2.9 \pm 10.7)\end{array}$ & $\begin{array}{c}29.4 \pm 9.8 \\
(-5.8 \pm 12.2)\end{array}$ \\
\hline TEWL $\left(\mathrm{g} / \mathrm{m}^{2} \cdot \mathrm{hr}\right)$ & $9.6 \pm 4.8$ & $8.7 \pm 2.1$ & $\begin{array}{c}9.6 \pm 2.9 \\
(0.0 \pm 4.8)\end{array}$ & $\begin{array}{l}10.3 \pm 3.4 \\
(1.6 \pm 3.1)\end{array}$ & $\begin{array}{c}9.6 \pm 4.0 \\
(-0.1 \pm 6.9)\end{array}$ & $\begin{array}{l}10.1 \pm 3.5 \\
(1.3 \pm 3.4)\end{array}$ \\
\hline $\mathrm{LEB}(\mu \mathrm{m})$ & $0.0 \pm 0.0$ & $9.0 \pm 42.2$ & $\begin{array}{c}0.0 \pm 0.0 \\
(0.0 \pm 0.0)\end{array}$ & $\begin{array}{c}0.0 \pm 0.0 \\
(-9.0 \pm 42.2)\end{array}$ & $\begin{array}{c}0.0 \pm 0.0 \\
(0.0 \pm 0.0)\end{array}$ & $\begin{array}{c}0.0 \pm 0.0 \\
(-9.0 \pm 42.2)\end{array}$ \\
\hline Skin thickness $(\mu \mathrm{m})$ & $1291.0 \pm 237.6$ & $1259.8 \pm 216.6$ & $\begin{array}{c}1302.9 \pm 245.7 \\
(12.0 \pm 243.2)\end{array}$ & $\begin{array}{c}1373.6 \pm 276.5 \\
(113.8 \pm 251.5)\end{array}$ & $\begin{array}{c}1326.5 \pm 282.9 \\
(64.5 \pm 266.5)\end{array}$ & $\begin{array}{l}1363.9 \pm 253.3 \\
(104.1 \pm 184.1)\end{array}$ \\
\hline Intensity & $26.3 \pm 12.3$ & $26.4 \pm 10.0$ & $\begin{array}{c}22.4 \pm 9.3 \\
(-3.9 \pm 10.0)\end{array}$ & $\begin{array}{c}21.7 \pm 7.6 \\
(-4.7 \pm 9.8)\end{array}$ & $\begin{array}{l}27.9 \pm 14.5 \\
(0.8 \pm 13.0)\end{array}$ & $\begin{array}{c}23.6 \pm 8.5 \\
(-2.7 \pm 8.2)\end{array}$ \\
\hline
\end{tabular}

Actual scores and changes from baseline (in parentheses) are shown as the mean and SD ( $\mathrm{n}=21$ for TSE and $\mathrm{n}=22$ for placebo). Baseline data were analyzed using Student's $t$-test. After the intervention data, the actual scores were analyzed using the linear mixed model, with the baseline data utilized as covariates and with time, group, group-time interaction, and subject as factors, and changes from baseline were analyzed using the linear mixed model, with time, group, group-time interaction, and subject as factors. No significant differences were detected between the TSE and placebo groups.

Table 5. Changes in AGEs parameters.

\begin{tabular}{|c|c|c|c|c|c|c|}
\hline & \multicolumn{2}{|c|}{ Baseline } & \multicolumn{2}{|c|}{$4 \mathrm{~W}$} & \multicolumn{2}{|c|}{$8 \mathrm{~W}$} \\
\hline & TSE & Placebo & TSE & Placebo & TSE & Placebo \\
\hline AGEs score in middle finger (a.u.) & $0.5 \pm 0.1$ & $0.5 \pm 0.1$ & $\begin{array}{c}0.5 \pm 0.1 \\
(0.0 \pm 0.1)\end{array}$ & $\begin{array}{c}0.5 \pm 0.1 \\
(0.0 \pm 0.1)\end{array}$ & $\begin{array}{c}0.5 \pm 0.1 \\
(0.0 \pm 0.1)\end{array}$ & $\begin{array}{c}0.5 \pm 0.1 \\
(0.0 \pm 0.1)\end{array}$ \\
\hline Serum pentosidine $(\mu \mathrm{g} / \mathrm{mL})$ & $0.055 \pm 0.006$ & $0.054 \pm 0.010$ & $\begin{array}{c}0.054 \pm 0.009 \\
(-0.001 \pm 0.008)\end{array}$ & $\begin{array}{c}0.053 \pm 0.011 \\
(-0.001 \pm 0.011)\end{array}$ & $\begin{array}{c}0.048 \pm 0.007^{\star} \\
\left(-0.007 \pm 0.007^{\star}\right)\end{array}$ & $\begin{array}{c}0.053 \pm 0.009 \\
(0.000 \pm 0.009)\end{array}$ \\
\hline Serum CML $(\mu \mathrm{g} / \mathrm{mL})$ & $4.18 \pm 4.60$ & $2.98 \pm 0.63$ & $\begin{array}{c}4.04 \pm 4.50 \\
(-0.13 \pm 0.28)\end{array}$ & $\begin{array}{c}2.84 \pm 0.60 \\
(-0.14 \pm 0.31)\end{array}$ & $\begin{array}{c}4.05 \pm 4.91 \\
(-0.16 \pm 0.35)\end{array}$ & $\begin{array}{c}2.82 \pm 0.53 \\
(-0.16 \pm 0.35)\end{array}$ \\
\hline
\end{tabular}

Actual scores and changes from baseline (in parentheses) are shown as the mean and SD ( $\mathrm{n}=21$ for TSE and $\mathrm{n}=22$ for placebo). Baseline data were analyzed using Student's $t$-test. After the intervention data, the actual scores were analyzed using the linear mixed model, with the baseline data utilized as covariates and with time, group, group-time interaction, and subject as factors, and changes from baseline were analyzed using the linear mixed model, with time, group, group-time interaction, and subject as factors. An asterisk indicates a significant difference from the placebo at ${ }^{*} p<0.05$. 


\subsection{Laboratory Data and Adverse Effects}

The blood pressure, pulse rate, body temperature, and serum IgE are listed in Table 1 and the blood hematology parameters are shown in Table 6. Except for blood pressure, no significant changes were observed between the 2 groups (Table 1). The biochemical parameters are shown in Table 7. After 8 weeks of intervention, significant differences were observed in the total protein between the 2 groups. However, this change was within the reference range. The urinalysis parameters did not change in either group (Table 8).

Table 6. Changes in hematology parameters.

\begin{tabular}{|c|c|c|c|c|c|}
\hline & \multicolumn{2}{|c|}{ Baseline } & \multicolumn{2}{|c|}{ After 8 weeks of ingestion } & \multirow[t]{2}{*}{ Standard value } \\
\hline & TSE & Placebo & TSE & Placebo & \\
\hline Red blood cells $\left(\times 10^{4}\right.$ cells $\left./ \mu \mathrm{L}\right)$ & $430 \pm 30$ & $446 \pm 38$ & $431 \pm 35$ & $447 \pm 37$ & $380-500$ \\
\hline Leukocytes (cells/ $\mu \mathrm{L})$ & $5333 \pm 1333$ & $5055 \pm 1371$ & $4765 \pm 1252$ & $5059 \pm 1452$ & $3300-9000$ \\
\hline Hemoglobin (g/dL) & $13.0 \pm 1.1$ & $13.4 \pm 0.9$ & $13.4 \pm 1.1$ & $13.6 \pm 0.8$ & $11.5-15.0$ \\
\hline Hematocrit (\%) & $41.7 \pm 2.8$ & $42.7 \pm 2.6$ & $41.7 \pm 2.9$ & $42.7 \pm 2.5$ & $34.8-45.0$ \\
\hline Platelets $\left(\times 10^{4}\right.$ cells $\left./ \mu \mathrm{L}\right)$ & $31.3 \pm 5.4$ & $27.4 \pm 5.0$ & $29.4 \pm 5.0$ & $27.0 \pm 5.2$ & $14.0-34.0$ \\
\hline Neutrophils (cells/ $\mu \mathrm{L})$ & $3152 \pm 1091$ & $2927 \pm 929$ & $2731 \pm 1026$ & $2929 \pm 940$ & \\
\hline Lymphocytes (cells/ $\mu \mathrm{L}$ ) & $1783 \pm 604$ & $1738 \pm 586$ & $1620 \pm 457$ & $1697 \pm 560$ & \\
\hline Monocytes (cells/ $\mu \mathrm{L})$ & $254 \pm 88$ & $234 \pm 67$ & $260 \pm 77$ & $264 \pm 78$ & \\
\hline Eosinophils (cells/ $\mu \mathrm{L})$ & $111 \pm 93$ & $121 \pm 78$ & $114 \pm 55$ & $125 \pm 66$ & \\
\hline Basophils (cells/ $\mu \mathrm{L})$ & $32.6 \pm 14.5$ & $34.5 \pm 18.9$ & $39.5 \pm 17.0$ & $44.9 \pm 12.4$ & \\
\hline
\end{tabular}

Each value is shown as the mean and SD ( $\mathrm{n}=21$ for TSE and $\mathrm{n}=22$ for placebo). Student's $t$-test was employed for the statistical analysis. No significant difference was detected between the placebo and TSE groups.

Table 7. Changes in biochemical parameters.

\begin{tabular}{cccccc}
\hline & \multicolumn{2}{c}{ Baseline } & \multicolumn{2}{c}{ After 8 weeks of ingestion } & Standard value \\
\cline { 2 - 5 } & TSE & Placebo & TSE & Placebo \\
\hline Total protein (g/dL) & $7.2 \pm 0.3$ & $7.3 \pm 0.4$ & $7.0 \pm 0.4$ & $7.3 \pm 0.4^{*}$ & $6.7-8.3$ \\
Total bilirubin (mg/dL) & $0.96 \pm 0.55$ & $0.80 \pm 0.25$ & $0.88 \pm 0.31$ & $0.86 \pm 0.32$ & $0.2-1.2$ \\
Urea N (mg/dL) & $12.7 \pm 3.1$ & $12.6 \pm 3.1$ & $12.4 \pm 3.0$ & $13.0 \pm 2.8$ & $8-20$ \\
Creatinine (mg/dL) & $0.61 \pm 0.07$ & $0.62 \pm 0.08$ & $0.59 \pm 0.08$ & $0.61 \pm 0.08$ & $0.47-0.79$ \\
Uric acid (mg/dL) & $4.1 \pm 1.0$ & $4.2 \pm 0.9$ & $3.9 \pm 1.0$ & $4.2 \pm 1.0$ & $2.5-7.0$ \\
Total cholesterol (mg/dL) & $235 \pm 27$ & $228 \pm 34$ & $239 \pm 24$ & $238 \pm 35$ & $120-219$ \\
LDL cholesterol (mg/dL) & $141 \pm 25$ & $133 \pm 33$ & $145 \pm 24$ & $140 \pm 34$ & $65-139$ \\
HDL cholesterol (mg/dL) & $75 \pm 15$ & $80 \pm 21$ & $78 \pm 15$ & $83 \pm 21$ & $40-95$ \\
Triglyceride (mg/dL) & $109 \pm 81$ & $78 \pm 30$ & $86 \pm 41$ & $78 \pm 34$ & $30-149$ \\
HbAlc (\%) & $5.3 \pm 0.3$ & $5.4 \pm 0.3$ & $5.3 \pm 0.3$ & $5.4 \pm 0.3$ & $4.6-6.2$ \\
Glycoalbumin (\%) & $14.2 \pm 1.4$ & $14.2 \pm 1.6$ & $13.7 \pm 1.5$ & $13.7 \pm 1.3$ & $12.3-16.5$ \\
Blood glucose (mg/dL) & $85 \pm 10$ & $84 \pm 6$ & $88 \pm 15$ & $83 \pm 8$ & $70-109$ \\
\hline
\end{tabular}




\section{Continued}

\begin{tabular}{|c|c|c|c|c|c|}
\hline Amylase (U/L) & $88 \pm 25$ & $86 \pm 31$ & $91 \pm 30$ & $85 \pm 24$ & $40-122$ \\
\hline CK (U/L) & $96 \pm 52$ & $108 \pm 53$ & $88 \pm 45$ & $116 \pm 50$ & $40-150$ \\
\hline AST (U/L) & $20.7 \pm 7.8$ & $21.3 \pm 4.5$ & $20.6 \pm 6.5$ & $21.8 \pm 5.7$ & $10-40$ \\
\hline $\operatorname{ALT}(\mathrm{U} / \mathrm{L})$ & $16.5 \pm 10.0$ & $17.0 \pm 9.7$ & $16.7 \pm 8.8$ & $17.1 \pm 10.1$ & $5-45$ \\
\hline$\gamma$-GTP $(\mathrm{U} / \mathrm{L})$ & $15.6 \pm 4.0$ & $17.0 \pm 7.2$ & $15.6 \pm 4.3$ & $17.7 \pm 7.9$ & $<30$ \\
\hline $\operatorname{ALP}(\mathrm{U} / \mathrm{L})$ & $173 \pm 56$ & $201 \pm 61$ & $165 \pm 52$ & $201 \pm 65$ & $100-325$ \\
\hline LAP (U/L) & $47 \pm 7$ & $49 \pm 6$ & $46 \pm 6$ & $50 \pm 5$ & $37-61$ \\
\hline LDH (U/L) & $187 \pm 32$ & $191 \pm 23$ & $183 \pm 31$ & $197 \pm 24$ & $120-240$ \\
\hline $\mathrm{Na}(\mathrm{mEq} / \mathrm{L})$ & $140 \pm 2$ & $140 \pm 2$ & $141 \pm 2$ & $140 \pm 1$ & $137-147$ \\
\hline $\mathrm{K}(\mathrm{mEq} / \mathrm{L})$ & $4.1 \pm 0.3$ & $4.2 \pm 0.3$ & $4.2 \pm 0.2$ & $4.2 \pm 0.3$ & $3.5-5.0$ \\
\hline $\mathrm{Cl}(\mathrm{mEq} / \mathrm{L})$ & $100 \pm 2$ & $100 \pm 2$ & $101 \pm 2$ & $101 \pm 1$ & $98-108$ \\
\hline $\mathrm{Ca}(\mathrm{mg} / \mathrm{dL})$ & $9.1 \pm 0.4$ & $9.3 \pm 0.3$ & $9.3 \pm 0.3$ & $9.4 \pm 0.3$ & $8.4-10.4$ \\
\hline $\mathrm{Fe}(\mu \mathrm{g} / \mathrm{dL})$ & $102 \pm 28$ & $103 \pm 25$ & $90 \pm 33$ & $102 \pm 33$ & $40-180$ \\
\hline Inorganic $\mathrm{P}(\mathrm{mg} / \mathrm{dL})$ & $3.8 \pm 0.5$ & $3.5 \pm 0.5$ & $3.7 \pm 0.3$ & $3.4 \pm 0.4$ & $2.5-4.5$ \\
\hline
\end{tabular}

Each value is shown as the mean and SD ( $\mathrm{n}=21$ for TSE and $\mathrm{n}=22$ for placebo). Student's $t$-test was employed for statistical analysis. An asterisk indicates a significant difference from the placebo at ${ }^{*}: p<0.05$.

Table 8. Changes in urine parameters.

\begin{tabular}{|c|c|c|c|c|}
\hline & Week & TSE & Placebo & Standard value \\
\hline \multirow{2}{*}{ Protein } & 0 & (nor):19, (ab):2 & $($ nor): $21,(a b): 1$ & \multirow{2}{*}{$(-)$} \\
\hline & 8 & (nor):19, (ab):1 & $($ nor): $20,(a b): 2$ & \\
\hline \multirow[t]{2}{*}{ Glucose } & 0 & (nor): $21,(\mathrm{ab}): 0$ & (nor):22, (ab):0 & \multirow[t]{2}{*}{$(-)$} \\
\hline & 8 & (nor):20, $(\mathrm{ab}): 0$ & (nor):22, (ab):0 & \\
\hline \multirow[t]{2}{*}{ Urobilinogen } & 0 & (nor): $21,(\mathrm{ab}): 0$ & $($ nor):22, (ab):0 & \multirow[t]{2}{*}{$( \pm)$} \\
\hline & 8 & (nor): $20,(\mathrm{ab}): 0$ & $($ nor):22, (ab):0 & \\
\hline \multirow[t]{2}{*}{ Bilirubin } & 0 & $($ nor) $: 21,(\mathrm{ab}): 0$ & (nor):22, (ab):0 & \multirow[t]{2}{*}{$(-)$} \\
\hline & 8 & $($ nor) $: 20,(\mathrm{ab}): 0$ & (nor):22, (ab):0 & \\
\hline \multirow[t]{2}{*}{$\mathrm{pH}$} & 0 & (nor):20, (ab):1 & (nor):22, (ab):0 & \multirow[t]{2}{*}{$(5.0-7.5)$} \\
\hline & 8 & (nor): $18,(\mathrm{ab}): 2$ & $($ nor): $21,(a b): 1$ & \\
\hline \multirow[t]{2}{*}{ Occult blood } & 0 & (nor):21, (ab):0 & (nor): $18,(\mathrm{ab}): 4$ & \multirow[t]{2}{*}{$(-)$} \\
\hline & 8 & (nor): $19,(\mathrm{ab}): 1$ & (nor):17, (ab):5 & \\
\hline \multirow[t]{2}{*}{ Ketone bodies } & 0 & (nor):20, (ab):1 & $($ nor): $21,(\mathrm{ab}): 1$ & \multirow[t]{2}{*}{$(-)$} \\
\hline & 8 & (nor): $19,(\mathrm{ab}): 1$ & (nor):22, (ab):0 & \\
\hline
\end{tabular}

Data are presented as the number of subjects with normal values (nor) or abnormal values (ab). The $\chi^{2}$-test was used for urinalysis parameters. No significant difference was detected between the placebo and TSE groups.

\section{Discussion}

Complaints about facial wrinkles and skin sagging from women increase with aging [42]. In healthy skin, the extracellular matrix (ECM) and dermal fibrob- 
lasts maintain the skin elasticity [43]. ECM is composed of elastin and collagen fibers [44], and elastin fibers consist of elastin and micro fibrils [45]. Decreases or denaturation of ECM or elastin fibers may cause deep wrinkles and skin sagging [42] [46]. In the normal metabolic process of collagen fibers, old collagen fibers are decomposed and then taken up by fibroblasts to be decomposed into amino acids, which are recycled as materials for new collagen synthesis [47] [48]. Thus, deterioration of collagen metabolism with aging is thought to change the skin's appearance [42]. Furthermore, the number of dermal fibroblasts decreases with skin senescence especially during the postmenopausal period, and collagen and elastin productions decline [49]. Therefore, recovering of collagen and elastin fiber production is promising to delay skin aging. For this purpose, ingestion of several food ingredients has been reported to be effective such as collagen peptides [50] and coenzyme Q10 [51].

Another factor for skin senescence is aging-related glycation of collagen [52]. Accumulation of AGEs in the dermis gives glycation stress to ECM [53]. Since the structure of elastin and collagen that form ECM become fragile with glycation, the skin is not able to maintain the structure and elasticity [52] [53]. To minimize the influence of dermal AGEs, oral supplementation of a cherry blossom extract [54] or mangosteen peel extract [55] are used.

In our current study, we examined the effect of continuous intake of TSE on the skin elasticity. The skin elasticity was evaluated by the value of viscoelasticity measured using a cutometer. The cutometer changes the tip of the probe into a negative pressure state, sucks the skin, and then opens it in the measurement process. R parameters including R1 to R9 represent the elasticity of the skin [56]. Regarding the R parameters in the study, significant differences were confirmed by TSE ingestion. R1 shows the ability to return to the original state after the first suction. When the value is closer to 0 , it means that elasticity is higher [57]. $\mathrm{R} 1$ and R4 were the same values in this study because R4 showed the ability to return to the original state after the final suction and we only sucked 1 time [57]. On the other hand, R2 shows the total elasticity over the measurement time and R5 shows the net elasticity at the time of suction. Moreover, R7 shows the ability of recovery corresponding to the maximum dented depth. A previous study on Japanese female subjects showed that the R2, R5, and R7 parameters correlated to age (29 to 55 years old or 31 to 59 years) [58] [59]. Thus, these parameters are suggested to reflect skin aging. In our study, the cheek R7 value of the TSE group at 8 weeks was higher than the placebo group (Table 2). The averaged ages of the subjects were 51 to 52 years old and the difference in R7 between the placebo and TSE groups was approximately 0.05 . A previously described study [59] showed that R7 decreased 0.008 per each year of age calculated from the approximate expression formula. Therefore, TSE is suggested to maintain cheek elasticity while cheek R7 value in placebo group changed toward aging about 6 to 7 years.

In addition, similarly, we applied the approximate expression [59] of R1, R2, and $\mathrm{R} 5$ to our study. As a result, R1 increases 0.002 per year of age, R2 decreases 
by 0.003 , and $\mathrm{R} 5$ decreases by 0.010 per year. When these trends are applied to our results, R1 and R5 are considered to prevent aging by about 6 to 7 years, and $\mathrm{R} 2$ is considered to be rejuvenated by about 23 to 25 years after 8 weeks of ingestion of TSE. Among these parameters, the tendency to deterioration were more common in the placebo group than TSE group. Therefore, it is considered that the systemic effect of TSE ingestion tended to suppress deterioration in the several parameters. From these results, it was shown that TSE intake is useful for maintaining cheek elasticity.

In terms of elasticity of the upper arms, a significant difference between the groups was confirmed only for R2 at 8 weeks (Table 3). The R2 of the upper arm in the TSE group was higher than that of the placebo group. The following are possible reasons why consistent results were not obtained in the upper arm in comparison to the cheek. Firstly, the subjects who were chosen had trouble with facial skin elasticity. However, it was unclear whether they had a similar problem with their upper arms. Another factor is the lack of randomization based on the elasticity of the upper arm. Therefore, further study is required to evaluate the effect of TSE on the elasticity of the upper arm by recruiting appropriate subjects.

As AGEs parameters in our study, the middle finger AGEs score and plasma pentosidine and CML were evaluated and no significant differences were found between the groups, however, the actual value and changed value of plasma pentosidine at 8 weeks were significantly lower in the TSE group compared to the placebo group (Table 5). Pentosidine is a cross-linkable AGE and is known to promote the formation of crosslinks by collagen glycation to cause a decrease in skin viscoelasticity [55]. In a study regarding the anti-glycation effect of mangosteen peel extract, healthy female subjects aged 32 to 48 years ingested the extract [55]. As a result, an improvement in the skin elasticity was observed with a decrease in pentosidine. Similarly, there was an improvement effect of TSE on the facial elasticity accompanied with pentosidine reduction.

There is still a question remaining. Regarding the fact that there was no change in the AGEs score of the middle finger, which is an index of glycation stress. The AGEs scores of the subjects of this study were in the range of healthy people aged 20 to 80 years old and the same as the averaged values for men and women [60]. Thus, it seems to be difficult to detect the influence of TSE. Moreover, CML is a non-crosslinking AGE and serum CML increases in a diabetic condition [61]. Since our study was conducted in healthy Japanese women, serum CML was in normal range. Thus, it is probable that the effect of TSE was not detected.

Finally, in the safety assessment, no side effects were identified during the study period under the conditions of this study, though adverse events were identified in some participants. However, based on the criteria set before the study, the investigator determined that there was no causal relationship with TSE. Physical measurements and serum parameters showed significant differences between the groups in terms of blood pressure throughout the study pe- 
riod, but the average values were within the standard values. In the biochemical parameters, there were some items that showed significant differences between the groups. However, the average value was within the standard value in all cases. Therefore, TSE was found to be safe to ingest under the conditions of the study.

In conclusion, TSE $(200 \mathrm{mg}$ ) standardized lycoperoside $\mathrm{H}$ ingestion was found to improve cheek elasticity. This effect seems to be beneficial for skin elasticity. Furthermore, the effect may suppress skin aging. Thus, further studies are required.

\section{Conclusion}

This study demonstrated that TSE (200 mg/day for 8 weeks) containing $1 \mathrm{mg}$ of lycoperoside $\mathrm{H}$ ameliorated skin elasticity in healthy female subjects with anxiety regarding facial skin elasticity. In addition, serum pentosidine was decreased by TSE. Therefore, TSE ingestion may contribute to skin elasticity. Furthermore, the intake of TSE was safe under the conditions of this study.

\section{Abbreviations}

AGEs, advanced glycation end products; ANCOVA, analysis of covariance; ANOVA, one-way analysis of variance; ALP, alkaline phosphatase; ALT, alanine transaminase; AST, aspartate aminotransferase; BMI, body mass index; CK, creatinine kinase; CML, (carboxymethyl) lysine; ELSD, evaporative light scattering detector; ECM, extracellular matrix; GTP, glutamyltransferase; HDL, high-density lipoprotein; Hb, hemoglobin; LAP, leucine aminopeptidase; LDH, lactate dehydrogenase; LDL, low-density lipoprotein; LEB, low echologenic band; SD, standard deviation; TEWL, trans epidermal water loss; TSE, tomato seed extract.

\section{Author Contributions}

The sponsor of the present study, Oryza Oil \& Fat Chemical Co., Ltd., assigned ORTHOMEDICO Inc. to conduct the study. S.T and H.S. (Ph.D.) are affiliated with Oryza Oil \& Fat Chemical Co., Ltd., and K.Y., N.S., S.Y., S.I., H.N., T.K., and A.S. are members of ORTHOMEDICO Inc. This study was conducted by both Oryza Oil \& Fat Chemical Co., Ltd. and Hiroo Dermatology Clinic \& Mentors Inc. I.T. (MD) was the principal investigator who monitored all the subjects' conditions. Furthermore, S.T., W.Y., and H.S. isolated and identified the chemical structure of lycoperoside.

\section{Acknowledgements and Funding}

This study was funded by Oryza Oil \& Fat Chemical Co. Ltd.

\section{Conflicts of Interest}

The authors declare no conflicts of interest regarding the publication of this paper. 


\section{References}

[1] Groten, K., Marini, A., Grether-Beck, S., Jaenicke, T., Ibbotson, S.H., Moseley, H., Ferguson, J. and Krutmann, J. (2019) Tomato Phytonutrients Balance UV Response: Results from a Double-Blind, Randomized, Placebo-Controlled Study. Skin Pharmacology and Physiology, 32, 101-108. https://doi.org/10.1159/000497104

[2] Chaudhary, P., Sharma, A., Singh, B. and Nagpal, A.K. (2018) Bioactivities of Phytochemicals Present in Tomato. Journal of Food Science and Technology, 55, 2833 2849. https://doi.org/10.1007/s13197-018-3221-Z

[3] Agarwal, S. and Rao, A.V. (2000) Tomato Lycopene and Its Role in Human Health and Chronic Diseases. Canadian Medical Association Journal, 163, 739-744.

[4] Imran, M., Ghorat, F., Ul-Haq, I., Ur-Rehman, H., Aslam, F., Heydari, M., Shariati, M.A., Okuskhanova, E., Yessimbekov, Z., Thiruvengadam, M., Hashempur, M.H. and Rebezov, M. (2020) Lycopene as a Natural Antioxidant Used to Prevent Human Health Disorders. Antioxidants, 9, Article No. 706. https://doi.org/10.3390/antiox9080706

[5] Stahl, W., Heinrich, U., Aust, O., Tronnier, H. and Sies, H. (2006) Lycopene-Rich Products and Dietary Photoprotection. Photochemical and Photobiological Sciences, 5 , 238-242. https://doi.org/10.1039/B505312A

[6] Rizwan, M., Rodriguez-Blanco, I., Harbottle, A., Birch-Machin, M.A., Watson, R.E. and Rhodes, L.E. (2010) Tomato Paste Rich in Lycopene Protects against Cutaneous Photodamage in Humans in Vivo: A Randomized Controlled Trial. British Journal of Dermatology, 164, 154-162. https://doi.org/10.1111/j.1365-2133.2010.10057.x

[7] Stahl, W., Heinrich, U., Wiseman, S., Eichler, O., Sies, H. and Tronnier, H. (2001) Dietary Tomato Paste Protects Against Ultraviolet Light-Induced Erythema in $\mathrm{Hu}$ mans. The Journal of Nutrition, 131, 1449-1451.

https://doi.org/10.1093/jn/131.5.1449

[8] Martínez-Huélamo, M., Vallverdú-Queralt, A., Di Lecce, G., Valderas-Martínez, P., Tulipani, S., Jáuregui, O., Escribano-Ferrer, E., Estruch, R., Illan, M. and Lamuela-Raventós, R.M. (2016) Bioavailability of Tomato Polyphenols Is Enhanced by Processing and Fat Addition: Evidence from a Randomized Feeding Trial. Molecular Nutrition \& Food Research, 60, 1578-1589. https://doi.org/10.1002/mnfr.201500820

[9] Yamamoto, T., Yoshimura, M., Yamaguchi, F., Kouchi, T., Tsuji, R., Saito, M., Obata, A. and Kikuchi, M. (2004) Anti-Allergic Activity of Naringenin Chalcone from a Tomato Skin Extract. Bioscience, Biotechnology, and Biochemistry, 68, 1706-1711. https://doi.org/10.1271/bbb.68.1706

[10] Nagula, R.L. and Wairkar, S. (2020) Cellulose Microsponges Based Gel of Naringenin for Atopic Dermatitis: Design, Optimization, in Vitro and in Vivo Investigation. International Journal of Biological Macromolecules. 164, 717-725.

https://doi.org/10.1016/j.ijbiomac.2020.07.168

[11] Tsai, M.J., Huang, Y.B., Fang, J.W., Fu, Y.S. and Wu, P.C. (2015) Preparation and Characterization of Naringenin-Loaded Elastic Liposomes for Topical Application. PLoS ONE, 10, e0131026. https://doi.org/10.1371/journal.pone.0131026

[12] Bhia, M., Motallebi, M., Abadi, B., Zarepour, A., Pereira-Silva, M., Saremnejad, F., Santos, A.C., Zarrabi, A., Melero, A., Jafari, S.M. and Shakibaei, M. (2021) Naringenin Nano-Delivery Systems and Their Therapeutic Applications. Pharmaceutics, 13, Article No. 291. https://doi.org/10.3390/pharmaceutics13020291

[13] Akrawi, S.H., Gorain, B., Nair, A.B., Choudhury, H., Pandey, M., Shah, J.N. and Venugopala, K.N. (2020) Development and Optimization of Naringenin-Loaded 
Chitosan-Coated Nanoemulsion for Topical Therapy in Wound Healing. Pharmaceutics, 12, Artilce No. 893. https://doi.org/10.3390/pharmaceutics12090893

[14] Al-Roujayee, A.S. (2017) Naringenin Improves the Healing Process of Thermally-induced Skin Damage in Rats. The Journal of Medical Internet Research, 45, 570582. https://doi.org/10.1177\%2F0300060517692483

[15] Karuppagounder, V., Arumugam, S., Thandavarayan, R.A., Sreedhar, R., Giridharan, V.V., Pitchaimani, V., Afrin, R., Harima, M., Krishnamurthy, P., Suzuki, K., Nakamura, M., Ueno, K. and Watanabe, K. (2016) Naringenin Ameliorates Skin Inflammation and Accelerates Phenotypic Reprogramming from M1 to M2 Macrophage Polarization in Atopic Dermatitis NC/Nga Mouse Model. Experimental Dermatology, 25, 404-407. https://doi.org/10.1111/exd.12962

[16] Kim, T.H., Kim, G.D., Ahn, H.J., Cho, J.J., Park, Y.S. and Park, C.S. (2013) The Inhibitory Effect of Naringenin on Atopic Dermatitis Induced by DNFB in NC/Nga Mice. Life Sciences, 93, 516-524. https://doi.org/10.1016/j.lfs.2013.07.027

[17] Martinez, R.M., Pinho-Ribeiro, F.A., Steffen, V.S., Caviglione, C.V., Vignoli, J.A., Barbosa, D.S., Baracat, M.M., Georgetti, S.R., Verri Jr., W.A. and Casagrande, R. (2015) Naringenin Inhibits UVB Irradiation-Induced Inflammation and Oxidative Stress in the Skin of Hairless Mice. Journal of Natural Products, 78, 1647-1655. https://doi.org/10.1021/acs.jnatprod.5b00198

[18] El-Mahdy, M.A., Zhu, Q., Wang, Q.E., Wani, G., Patnaik, S., Zhao, Q., Arafa, El.-S., Barakat, B., Mir, S.N. and Wani, A.A. (2008) Naringenin Protects HaCaT Human Keratinocytes Against UVB-Induced Apoptosis and Enhances the Removal of Cyclobutane Pyrimidine Dimers from the Genome. Photochemistry and Photobiology, 84, 307-316. https://doi.org/10.1111/j.1751-1097.2007.00255.x

[19] Martinez, R.M., Pinho-Ribeiro, F.A., Steffen, V.S., Silva, T.C., Caviglione, C.V., Bottura, C., Fonseca, M.J., Vicentini, F.T., Vignoli, J.A., Baracat, M.M., Georgetti, S.R., Verri Jr., W.A. and Casagrande, R. (2016) Topical Formulation Containing Naringenin: Efficacy Against Ultraviolet B Irradiation-Induced Skin Inflammation and Oxidative Stress in Mice. PLoS ONE, 11, e0146296.

https://doi.org/10.1371/journal.pone.0146296

[20] Jung, S.K., Ha, S.J., Jung, C.H., Kim, Y.T., Lee, H.K., Kim, M.O., Lee, M.H., Mottamal, M., Bode, A.M., Lee, K.W. and Dong, Z. (2016) Naringenin Targets ERK2 and Suppresses UVB-Induced Photoaging. Jounal of Cellular and Molecular Medicine, 20, 909-919. https://doi.org/10.1111/jcmm.12780

[21] Nasr Bouzaiene, N., Chaabane, F., Sassi, A., Chekir-Ghedira, L. and Ghedira, K. (2016) Effect of Apigenin-7-Glucoside, Genkwanin and Naringenin on Tyrosinase Activity and Melanin Synthesis in B16F10 Melanoma Cells. Life Sciences. 144, 80-85. https://doi.org/10.1016/j.lfs.2015.11.030

[22] Nohara, T., Ono, M., Ikeda, T., Fujiwara, Y. and El-Aasr, M. (2010) The Tomato Saponin, Esculeoside A. Journal of Natural Products, 73, 1734-1741. https://doi.org/10.1021/np100311t

[23] Nielen, M.W.F. and Van Beek, T.A. (2014) Macroscopic and Microscopic Spatially-Resolved Analysis of Food Contaminants and Constituents Using Laser-Ablation Electrospray Ionization Mass Spectrometry Imaging. Analytical and Bioanalytical Chemistry, 406, 6805-6815. https://doi.org/10.1007/s00216-014-7948-8

[24] Yahara, S., Uda, N. and Nohara, T. (1996) Lycoperosides A-C, Three Stereoisomeric 23-Acetoxyspirosolan-3 $\beta$-ol $\beta$-Lycotetraosides from Lycopersicon esculentum. Phytochemistry, 42, 169-172. https://doi.org/10.1016/0031-9422(95)00854-3

[25] Fujiwara, Y., Yahara, S., Ikeda, T., Ono, M. and Nohara, T. (2003) Cytotoxic Major 
Saponin from Tomato Fruits. Chemical and Pharmaceutical Bulletin, 51, 234-235. https://doi.org/10.1248/cpb.51.234

[26] Fujiwara, Y., Takaki, A., Uehara, Y., Ikeda, T., Okawa, M., Yamauchi, K., Ono, M., Yoshimitsu, H. and Nohara, T. (2004) Tomato Steroidal Alkaloid Glycosides, Esculeosides A and B, from Ripe Fruits. Tetrahedron, 60, 4915-4920.

https://doi.org/10.1016/j.tet.2004.03.088

[27] Nohara, T., Fujiwara, Y., Zhou, J.R., Urata, J., Ikeda, T., Murakami, K., El-Aasr, M. and Ono, M. (2015) Saponins, Esculeosides B-1 and B-2, in Tomato Juice and Sapogenol, Esculeogenin B1. Chemical and Pharmaceutical Bulletin, 63, 848-850. https://doi.org/10.1248/cpb.c15-00449

[28] Ono, M., Takara, Y., Egami, M., Uranaka, K., Yoshimitsu, H., Matsushita, S., Fujiwara, Y., Ikeda, T. and Nohara, T. (2006) Steroidal Alkaloid Glycosides, Esculeosides C and D, from the Ripe Fruit of Cherry Tomato. Chemical and Pharmaceutical Bulletin, 54, 237-239. https://doi.org/10.1248/cpb.54.237

[29] Yoshizaki, M., Matsushita, S., Fujiwara, Y., Ikeda, T., Ono, M. and Nohara, T. (2005) Tomato New Sapogenols, Isoesculeogenin A and Esculeogenin B. Chemical and Pharmaceutical Bulletin, 53, 839-840. https://doi.org/10.1248/cpb.53.839

[30] Ito, S., Ihara, T., Tamura, H., Tanaka, S., Ikeda, T., Kajihara, H., Dissanayake, C., Abdel-Motaal, F.F. and El-Sayed, M.A. (2007) $\alpha$-Tomatine, the Major Saponin in Tomato, Induces Programmed Cell Death Mediated by Reactive Oxygen Species in the Fungal Pathogen Fusarium oxysporum. FEBS Letters. 581, 3217-3222. https://doi.org/10.1016/j.febslet.2007.06.010

[31] Zhou, J.R., Urata, J., Shiraishi, T., Tanaka, C., Nohara, T. and Yokomizo, K. (2018) Tomato Juice Saponin, Esculeoside B Ameliorates Mice Experimental Dermatitis. Functional Foods in Health and Disease, 8, 228-241. https://doi.org/10.31989/ffhd.v8i4.420

[32] Zhou, J.R., Kanda, Y., Tanaka, A., Manabe, H., Nohara, T. and Yokomizo, K. (2016) Anti-Hyaluronidase Activity in Vitro and Amelioration of Mouse Experimental Dermatitis by Tomato Saponin, Esculeoside A. Journal of Agricultural and Food Chemistry, 64, 403-408. https://doi.org/10.1021/acs.jafc.5b05320

[33] Takeda, S., Miyasaka, K. and Shimoda, H. (2021) Lycoperoside H, a Steroidal Alkaloid Saponin in Tomato Seeds, Ameliorates Atopic Dermatitis-like Symptoms in IL-33 Transgenic Mice. Journal of Food Biochemistry, e13877. https://doi.org/10.1111/jfbc.13877

[34] Damkerngsuntorn, W., Rerknimitr, P., Panchaprateep, R., Tangkijngamvong, N., Kumtornrut, C., Kerr, S.J., Asawanonda, P., Tantisira, M.H. and Khemawoot, P. (2020) The Effects of a Standardized Extract of Centella asiatica on Postlaser Resurfacing Wound Healing on the Face: A Split-Face, Double-Blind, Randomized, Placebo-Controlled Trial. Journal of Alternative and Complementary Medicine, 26, 529-536. https://doi.org/10.1089/acm.2019.0325

[35] Paocharoen, V. (2010) The Efficacy and Side Effects of Oral Centella asiatica Extract for Wound Healing Promotion in Diabetic Wound Patients. Journal of the Medical Association of Thailand, 93, 166-170.

[36] De Sanctis, M.T., Cesarone, M.R., Incandela, L., Belcaro, G., Ricci, A. and Griffin, M. (2001) Four-Week Treatment with Essaven Gel in Diabetic Microangiopathy-A Placebo-Controlled, Randomized Study. Angiology, 52, 49-55. https://doi.org/10.1177\%2F0003319701052003S10

[37] De Sanctis, M.T., Cesarone, M.R., Incandela, L., Belcaro, G. and Griffin, M. (2001) Treatment of Superficial Vein Thrombosis with Standardized Application of Essa- 
ven Gel-A Placebo-Controlled, Randomized Study. Angiology, 3, 57-62. https://doi.org/10.1177/0003319701052003S11

[38] Incandela, L., Belcaro, G., Nicolaides, A.N., Geroulakos, G., Cesarone, M.R. and De Sanctis, M.T. (2001) Microcirculation after Standardized Application of Essaven Gel on Normal Skin-A Placebo-Controlled, Randomized Study. Angiology, 3, 5-10. https://doi.org/10.1177\%2F0003319701052003S03

[39] Ghosh, R. and Kline, P. (2019) HPLC with Charged Aerosol Detector (CAD) as a Quality Control Platform for Analysis of Carbohydrate Polymers. BMC Research Notes, 12, Article No. 268. https://doi.org/10.1186/s13104-019-4296-y

[40] Woo, M.S., Moon, K.J., Jung, H.Y., Park, S.R., Moon, T.K., Kim, N.S. and Lee, B.C. (2014) Comparison of Skin Elasticity Test Results from the Ballistometer ${ }^{\circledR}$ and $\mathrm{Cu}-$ tometer ${ }^{\circledR}$. Skin Research and Technology, 20, 422-428.

https://doi.org/10.1111/srt.12134

[41] Adatto, M., Adatto-Neilson, R., Servant, J.J., Vester, J., Novak, P. and Krotz, A. (2010) Controlled, Randomized Study Evaluating the Effects of Treating Cellulite with AWT/EPAT. Journal of Cosmetic and Laser Therapy, 12, 176-182. https://doi.org/10.3109/14764172.2010.500392

[42] Flament, F., Abric, A., Amar, D., Ye, C., Caron, J. and Negre, C. (2020) Changes in Facial Signs Due to Age and Their Respective Weights on the Perception of Age, on a Tired-Look or a Healthy Glow among Differently Aged Chinese Men. International Journal of Cosmetic Science, 42, 452-461. https://doi.org/10.1111/ics.12649

[43] Halper, J. and Kjaer, M. (2014) Basic Components of Connective Tissues and Extracellular Matrix: Elastin, Fibrillin, Fibulins, Fibrinogen, Fibronectin, Laminin, Tenascins and Thrombospondins. In: Halper, J., Eds., Progress in Heritable Soft Connective Tissue Diseases, Vol. 802, Springer, Dordrecht, 31-47. https://doi.org/10.1007/978-94-007-7893-1_3

[44] Lo, S. and Fauzi, M.B. (2021) Current Update of Collagen Nanomaterials-Fabrication, Characterisation and Its Applications: A Review. Pharmaceutics, 13, Article No. 316. https://doi.org/10.3390/pharmaceutics13030316

[45] Langton, A.K., Hann, M., Costello, P., Halai, P., Sisto Alessi César, S., Lien-Lun Chien, A., Kang, S., Griffiths, C.E.M., Sherratt, M.J. and Watson, R.E.B. (2020) Heterogeneity of Fibrillin-Rich Microfibrils Extracted from Human Skin of Diverse Ethnicity. Journal of Anatomy, 237, 478-486. https://doi.org/10.1111/joa.13217

[46] Chowdhury, A., Nosoudi, N., Karamched, S., Parasaram, V. and Vyavahare, N. (2021) Polyphenol Treatments Increase Elastin and Collagen Deposition by Human Dermal Fibroblasts; Implications to Improve Skin Health. Journal of Dermatological Science, 102, 94-100. https://doi.org/10.1016/j.jdermsci.2021.03.002

[47] Tang, S., Lucius, R., Wenck, H., Gallinat, S. and Weise, J.M. (2013) UV-Mediated Downregulation of the Endocytic Collagen Receptor, Endo180, Contributes to Accumulation of Extracellular Collagen Fragments in Photoaged Skin. Journal of Dermatological Science, 70, 42-48. https://doi.org/10.1016/j.jdermsci.2013.01.008

[48] Engelholm, L.H., List, K., Netzel-Arnett, S., Cukierman, E., Mitola, D.J., Aaronson, H., Kjøller, L., Larsen, J.K., Yamada, K.M., Strickland, D.K., Holmbeck, K., Danø, K., Birkedal-Hansen, H., Behrendt, N. and Bugge, T.H. (2003) uPARAP/Endo180 is Essential for Cellular Uptake of Collagen and Promotes Fibroblast Collagen Adhesion. Journal of Cell Biology, 160, 1009-1015. https://doi.org/10.1083/jcb.200211091

[49] Lephart, E.D. and Naftolin, F. (2021) Menopause and the Skin: Old Favorites and New Innovations in Cosmeceuticals for Estrogen-Deficient Skin. Dermatology and Therapy, 11, 53-69. https://doi.org/10.1007/s13555-020-00468-7 
[50] Proksch, E., Segger, D., Degwert, J., Schunck, M., Zague, V. and Oesser, S. (2014) Oral Supplementation of Specific Collagen Peptides Has Beneficial Effects on $\mathrm{Hu}$ man Skin Physiology: A Double-Blind, Placebo-Controlled Study. Skin Pharmacology and Physiology, 27, 47-55. https://doi.org/10.1159/000351376

[51] Žmitek, K., Pogačnik, T., Mervic, L., Žmitek, J. and Pravst, I. (2017) The Effect of Dietary Intake of Coenzyme Q10 on Skin Parameters and Condition: Results of a Randomized, Placebo-Controlled, Double-Blind Study. Biofactors, 43, 132-140. https://doi.org/10.1002/biof.1316

[52] Yonei, Y., Takabe, W. and Yagi, M. (2015) Photoaging and Glycation of Elastin: Effect on Skin. Glycative Stress Research, 2, 182-190.

[53] Zarkovic, K., Larroque-Cardoso, P., Pucelle, M., Salvayre, R., Waeg, G., Nègre-Salvayre, A. and Zarkovic, N. (2015) Elastin Aging and Lipid Oxidation Products in Human Aorta Redox Biology, 4, 109-117. https://doi.org/10.1016/j.redox.2014.12.008

[54] Matsuyama, A., Kikuchi, M. and Shimoda, H. (2018) Effect on Skin Condition by 8-Week Ingestion of Standardized Cherry Blossom Flower Extract (Sakura Extract-P). International Journal of Biomedical Science, 14, 12-19.

[55] Takabe, W., Yagi, M., Ogura, M. and Yonei, Y. (2017) Effect of Mangosteen Pericarp Extract-Containing Black Vinegar Drink on Skin Quality through Anti-Glycative Actions. Glycative Stress Research, 4, 158-171. https://doi.org/10.24659/gsr.4.3_158

[56] Lee, K.C., Dretzke, J., Grover, L., Logan, A. and Moiemen, N. (2016) A Systematic Review of Objective Burn Scar Measurements. Burns \& Trauma, 4, Article ID: s41038016-0036-x. https://doi.org/10.1186/s41038-016-0036-x

[57] Kawałkiewicz, W., Matthews-Kozanecka, M., Janus-Kubiak, M., Kubisz, L. and Hojan-Jezierska, D. (2021) Instrumental Diagnosis of Facial Skin-A Necessity or a Pretreatment Recommendation in Esthetic Medicine. Journal of Cosmetic Dermatology, 20, 875-883. https://doi.org/10.1111/jocd.13638

[58] Ohshima, H., Kinoshita, S., Oyobikawa, M., Futagawa, M., Takiwaki, H., Ishiko, A. and Kanto, H. (2012) Use of Cutometer Area Parameters in Evaluating Age-Related Changes in the Skin Elasticity of the Cheek. Skin Research and Technology, 19, e238-e242. https://doi.org/10.1111/j.1600-0846.2012.00634.x

[59] Ezure, T. and Amano, S. (2010) Influence of Subcutaneous Adipose Tissue Mass on Dermal Elasticity and Sagging Severity in Lower Cheek. Skin Research and Technology, 16, 332-338. https://doi.org/10.1111/j.1600-0846.2010.00438.x

[60] Morita, Y., Yagi, M., Ishizaki, K., Takabe, W., Komatsu, T., Nakazawa, M., Matsushima, M., Urata, T. and Yonei, Y. (2019) Evaluation of the Glycative Stress by Non-Invansive Skin AGEs Measurement Devices. Glycative Stress Research, 6, 92-102. https://doi.org/10.24659/gsr.6.2_92

[61] Tan, S.M.Q., Chiew, Y., Ahmad, B. and Kadir, K.A. (2018) Tocotrienol-Rich Vitamin E from Palm Oil (Tocovid) and Its Effects in Diabetes and Diabetic Nephropathy: A Pilot Phase II Clinical Trial. Nutrients, 10, Article No. 1315. https://doi.org/10.3390/nu10091315 